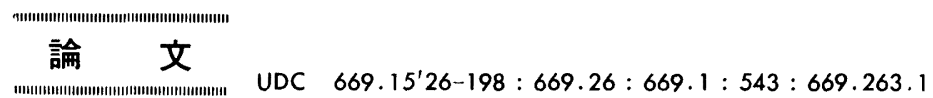

\title{
半還元クロムペレット中の金属クロム及び金属鉄の定量法*
}

\author{
奥田欽之助 ${ }^{* *}$. 村中貢 ${ }^{* *} \cdot$ 武田 㐘雄** \\ 阿部浩**. 桜井 良治**. 後藤 一義**
}

\section{Chemical Analysis of Metallic Chromium and Iron Contained in Semi-reduced Chromium Pellet}

\author{
Kinnosuke OKudA, Mitsugu MuranaKa, Kikuo TAKeda, \\ Hiroshi Abe, Ryōji SAKurai, and Kazuyoshi Gotō
}

\begin{abstract}
Synopsis:
Chemical analysis of metallic chromium and iron contained in semi-reduced pellet produced in ferrochromium factory was studied. Metallic $\mathrm{Cr}$ and $\mathrm{Fe}$ form complex carbide which is easily dissolved in concentrated $\mathrm{H}_{2} \mathrm{SO}_{4}$. However, when acid concentration was high, higher analytical values of $\mathrm{Cr}$ and $\mathrm{Fe}$ were obtained because of the dissolution of $\mathrm{Cr}$ and $\mathrm{Fe}$ from unreacted chromite ore which was contained in the semireduced pellet. $\mathrm{H}_{2} \mathrm{SO}_{4}(1+3)$ was most suitable to fully recover metallic $\mathrm{Cr}$ and $\mathrm{Fe}$ preventing the dissolution of chromite. Another important point was to put a condensation cooler over a beaker to maintain constant volume and concentration of acid during heating period. The boiling point of $\mathrm{H}_{2} \mathrm{SO}_{4}(1+3)$ was kept to $111^{\circ} \mathrm{C}$. Under this condition being maintained for 30 minutes, the best result was obtained. The proposed method had no bias among four laboratories and precision of the method was as follows;

for metallic $\mathrm{Cr}$, the standard deviation was $0.15 \%$ to mean value of $13.6 \%$.

for metallic $\mathrm{Fe}$, the standard deviation was $0.20 \%$ to mean value of $11.0 \%$.
\end{abstract}

\section{1. 緒言}

高炭素フェロクロムを製造する一方法として，クロム 鉣石と炭材を粉㸞混合してペレットにし，ロータリキル ンで約 $1450^{\circ} \mathrm{C}$ をで昇温させて，鉄を $80 \%$ ，クロムを 50\%程度還元させる方法がある.このようないわゆる半 還元ペレットについて，その還元率を求めるためには， ペレット中の金属クロムおよび金属鉄の分析が全クロム および全鉄の分析とともに必要である.

この金属クロムおよび金属鉄の分析法については，ク ロムおよび鉄の複合炭化物の分析を対象とすると同時に 共存する末還元のクロム鉱石からのクロムおよび鉄の溶 出についても考虑せねばならない，このような金属ク口 ムおよび金属鉄の抽出については，前述の製造法の基本 となる特許公告1)に「硫酸の10\% 水溶液に溶けること をもつて金属クロムおよび金属鉄とする」ことを示して いるにすぎない。このほか，LLOYD2) は「フェロクロム

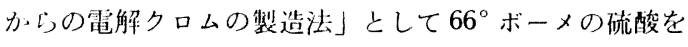

使州しているが，この時は酸化ク口ムも溶出する旨指摘 している.

われわれの工場では，本製咀法の工業化にあたり，こ の金属クロムおよび金属鉄の分析法を研究し，次の方法 准用されていた。

試料 $0.5 \mathrm{~g}$ をとり硫酸 $(1+1) 40 \mathrm{ml}$ を加えて水浴中 にビーカーを置き, 試料液温 $80^{\circ} \mathrm{C} て ゙ 60 \mathrm{~min}$ 間加熱す る・ついで放冷したのち沪過し，沪液の一部を分取して JIS-G1313「フェロクロム分析法」によりクロムを, JIS-M8263「クロム鉙石中の鉄定量法」により鉄を䇥 量し，この定量法をもつてペレット中の金属クロムおよ び金属鉄とする.

この方法による硫酸抽出残椬をX線回折により，その 主構成物を同定与ると，Fig. 1 にみられるように酸化物 のみから成り，原試料にみられたクロム一鉄炭化物のピ 一クは消失している.

しかしこの方法による分析䛊学は約 $20 \%$ の金属ク 口ムに対し， $\sigma=0.80 \%$ ，約 $10 \%$ の金属鉄に刘し， $\sigma=$

* 昭和 50 年 10 月本会講演大会にて発表 昭和 51 年 5 月 17 日受付 (Received May 17, 1976)

** 日本重化学工業(株) (Japan Metals \& Chemicals Co. 8-4, Koamicho Nihonbashi Chūo-ku Tokyo 103) 

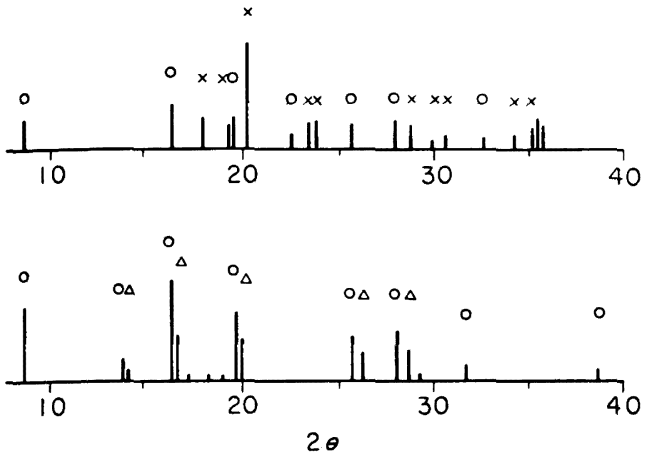

$x:\left(\mathrm{Cr}_{1} \mathrm{Fe}\right)_{7} \mathrm{C}_{3} \quad \mathrm{O}: \mathrm{Fe}(\mathrm{Al}, \mathrm{Cr})_{2} \mathrm{O}_{4} \quad \Delta: \mathrm{Fe} \quad \mathrm{Al}_{2} \mathrm{O}_{4}$

(Target : Mo, Filter : Zr, $40 \mathrm{kVA}, 20 \mathrm{~mA}$ )

Fig. 1. X-ray diffraction pattern of semi-reduced pellet (upper) and its residue leached with $\mathrm{H}_{2} \mathrm{SO}_{4}(1+1)$ at $80^{\circ} \mathrm{C}$ (lower).

Table 1. Analytical value of samples.

\begin{tabular}{c|c|c|c|c}
\hline Sample & Gr & Fe & Si & C \\
\hline Metallic Cr & 96.8 & 0.79 & 0.09 & 0.002 \\
FCrH 1 & 68.1 & 23.4 & 0.68 & 6.79 \\
FCrH 5 & 59.8 & 25.7 & 5.75 & 7.29 \\
$\mathrm{Cr}_{7} \mathrm{C}_{3}$ & 86.8 & 0.60 & 0.47 & 11.6 \\
$\mathrm{Cr}_{3} \mathrm{C}_{2}$ & 83.2 & 0.79 & 0.30 & 14.9 \\
\hline
\end{tabular}

(FCrH is a sign of JISG 2303 for high carbon-ferrochromium.)

$0.49 \%$ とかなり大きく，また分析所間の測定値に差が みられた。 これに加えて抽出時間の $60 \mathrm{~min}$ 乙程管理 上もつと短縮したい，という要望もあつたので再検討を 行なつた. その結果, 硫酸濃度として, $(1+3)$ が楜当 であり, 還流冷却器をつけてその沸点を保ちながら 30 min 抽出を行なら方法を最適と認めたのでその概要を 報告する。

\section{2. 予 備 実 験}

まず現行の抽出法により抽出されるクロムの形態を調 ベるため,ささざをな形態のクロムを含有する試料につ いて前述の分析法で 1 5h の抽出を行なつた，供試料 の記号及び分析値を Table 1 に示寸. また, その結果 を Fig. 2 に示す. なお，試莧の酸化クロムをも実験に 供したが，そのクロム抽出率は 1 〜 h にわたりゼロで あつた。 Fig. 2 の結果つぎの結論を得た。

（i）金属クロムは，ほほ完全に抽出される.

(ii）フェロクロムは，けい素の含有量が低いときは 金属クロムと同㥞によく抽出されるが，けい素の 含有量が高いと，その抽出率は低下する.

（iii）鉄を含まないクロム炭化物は，抽出率が低い。 二酸化けい素の炭素による還元反応で，金属けい素が

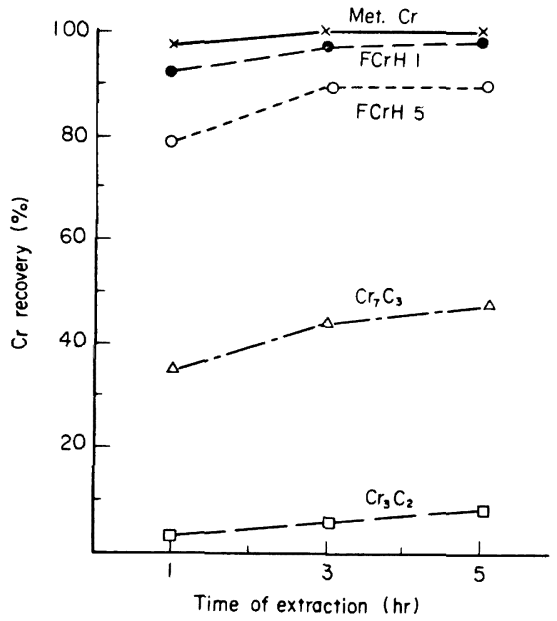

Fig. 2. Cr recovery of various $\mathrm{Cr}$ compounds by $\mathrm{H}_{2} \mathrm{SO}_{4}(1+1)$ leaching.

Table 2. Factors and levels of the experimental design.

\begin{tabular}{|c|c|c|}
\hline \multirow{2}{*}{ Factor } & \multicolumn{2}{|c|}{ Level } \\
\hline & ( 1 ) & (2) \\
\hline Heating method (A) & $\begin{array}{l}\text { Sand bath, } \\
\text { with a } \\
\text { condensor }\end{array}$ & $\begin{array}{l}\text { Water bath, } \\
\text { open }\end{array}$ \\
\hline Heating time (B) & $\begin{array}{l}30 \min \text { for } A_{1} \\
60 \min \text { for } A_{2}\end{array}$ & $\begin{array}{l}15 \min \text { for } A_{1} \\
30 \min \text { for } A_{2}\end{array}$ \\
\hline $\begin{array}{l}\text { Concentration } \\
\text { of } \mathrm{H}_{2} \mathrm{SO}_{4}\end{array}$ & $(1+1)$ & $(1+10)$ \\
\hline $\begin{array}{l}\text { Weight of } \\
\text { sample }\end{array}$ & $1.0 \mathrm{~g}$ & $0.5 \mathrm{~g}$ \\
\hline Size of sample (E) & $-200^{\text {Mesh }}$ & $-100^{\mathrm{Mesh}}$ \\
\hline $\begin{array}{l}\text { Reduction rate }(R) \\
\text { of sample }\end{array}$ & $\begin{array}{l}20 \% \text { for } \mathrm{Cr} \\
50 \% \text { for } \mathrm{Fe}\end{array}$ & $\begin{array}{l}50 \% \text { for } \mathrm{Cr} \\
90 \% \text { for } \mathrm{Fe}\end{array}$ \\
\hline
\end{tabular}

生成するのは, 熱力学データーにより $1700^{\circ} \mathrm{C}$ 以上と推 定される3)。また鉄の存在の下では，この反応開始温度 は，低下寸る傾向にあるがそれでも $1500^{\circ} \mathrm{C}$ 以下では金 属けい素は生成しない4)。

本研究の対象となる半還元ペレットは, 最高反応温度 が $1450^{\circ} \mathrm{C}$ であり，金属けい素の生成はいまだ起こつて いないまたその金属生成物も，Fig. 1亿示されるよう に，クロム一鉄炭化物であるので，硫酸抽出法が適当で あるといえる。

\section{3. 改良法の研究}

\section{$3 \cdot 1 \mathbf{L}_{16}$ 型の実験}


金属クロムおよび金属鉄の分析值に及ぼす要因につい て, 工場分析者とともに検討し, 特性要因図を作成し, いくつかの予備実験を行なつたうえ, Table 2 の要因と 水準を選えで $\mathrm{L}_{16}$ 型の直交配列による実験を行なつた.

このうち，ペレットの還元乘は通常，クロムで $50 \%$, 鉄で 90\% であるが，工程变動としてクロムで 20\%， 鉄で 50\% の範囲まで生産される. したがつて Table 1 では高還元率のパレットと低還元㵏のものと 2 水準を採
つた，高還元率の場合，金属クロムは約 $18 \%$ で，低還 元率では的 $6 \%$ と，相当低くなる. 金属鉄についてもほ ぼ同様である．そこで還元率をブロック因子として，16 $\times 2$ 回の実験を行なつた. 実験方法は 1 節で述べた方法 に準し，それぞれの要因および水準を適用し，特性值と して，金属クロムおよび金属鉄を測定した．実験結果を Table 3 に, その分散分析結果を Table 4, 5 に示す. 分散分析表にみられるように，各因子の金属クロムに

Table 3. Experimental results of $\mathrm{L}_{16}$ design.

\begin{tabular}{|c|c|c|c|c|c|c|c|c|c|}
\hline Factor & A & B & $\mathrm{C}$ & D & $\mathrm{E}$ & \multicolumn{2}{|c|}{$\mathrm{R}_{1}$} & \multicolumn{2}{|c|}{$\mathrm{R}_{2}$} \\
\hline No. & 2 & 1 & 8 & 6 & 12 & $\mathrm{Cr}$ & $\mathrm{Fe}$ & $\mathrm{Cr}$ & $\mathrm{Fe}$ \\
\hline $\begin{array}{l}1 \\
2 \\
3 \\
4\end{array}$ & $\begin{array}{l}1 \\
1 \\
1 \\
1\end{array}$ & $\begin{array}{l}1 \\
1 \\
1 \\
1\end{array}$ & $\begin{array}{l}1 \\
2 \\
1 \\
2\end{array}$ & $\begin{array}{l}1 \\
1 \\
2 \\
2\end{array}$ & $\begin{array}{l}1 \\
2 \\
2 \\
1\end{array}$ & $\begin{array}{l}7.6 \\
7.0 \\
7.1 \\
6.7\end{array}$ & $\begin{array}{l}6.4 \\
5.7 \\
6.2 \\
5.9\end{array}$ & $\begin{array}{l}19.5 \\
18.6 \\
19.8 \\
19.0\end{array}$ & $\begin{array}{l}15.0 \\
14.7 \\
15.0 \\
15.0\end{array}$ \\
\hline $\begin{array}{l}5 \\
6 \\
7 \\
8\end{array}$ & $\begin{array}{l}2 \\
2 \\
2 \\
2\end{array}$ & $\begin{array}{l}1 \\
1 \\
1 \\
1\end{array}$ & $\begin{array}{l}1 \\
2 \\
1 \\
2\end{array}$ & $\begin{array}{l}2 \\
2 \\
1 \\
1\end{array}$ & $\begin{array}{l}1 \\
2 \\
2 \\
1\end{array}$ & $\begin{array}{l}3.7 \\
0.4 \\
1.2 \\
3.4\end{array}$ & $\begin{array}{l}4.0 \\
2.1 \\
2.7 \\
3.2\end{array}$ & $\begin{array}{l}18.7 \\
14.5 \\
18.4 \\
13.8\end{array}$ & $\begin{array}{l}14.0 \\
11.2 \\
14.0 \\
12.5\end{array}$ \\
\hline $\begin{array}{r}9 \\
10 \\
11 \\
12\end{array}$ & $\begin{array}{l}1 \\
1 \\
1 \\
1\end{array}$ & $\begin{array}{l}2 \\
2 \\
2 \\
2\end{array}$ & $\begin{array}{l}1 \\
2 \\
1 \\
2\end{array}$ & $\begin{array}{l}1 \\
1 \\
2 \\
2\end{array}$ & $\begin{array}{l}1 \\
2 \\
2 \\
1\end{array}$ & $\begin{array}{l}7.1 \\
3.4 \\
7.0 \\
4.7\end{array}$ & $\begin{array}{l}7.0 \\
4.4 \\
6.1 \\
4.7\end{array}$ & $\begin{array}{l}19.6 \\
15.6 \\
19.6 \\
16.5\end{array}$ & $\begin{array}{l}15.6 \\
13.0 \\
15.0 \\
13.3\end{array}$ \\
\hline $\begin{array}{l}13 \\
14 \\
15 \\
16\end{array}$ & $\begin{array}{l}2 \\
2 \\
2 \\
2\end{array}$ & $\begin{array}{l}2 \\
2 \\
2 \\
2\end{array}$ & $\begin{array}{l}1 \\
2 \\
1 \\
2\end{array}$ & $\begin{array}{l}2 \\
2 \\
1 \\
1\end{array}$ & $\begin{array}{l}1 \\
2 \\
2 \\
1\end{array}$ & $\begin{array}{l}0.4 \\
0.8 \\
0.5 \\
0.6\end{array}$ & $\begin{array}{l}2.5 \\
2.2 \\
2.1 \\
2.2\end{array}$ & $\begin{array}{r}15.5 \\
6.0 \\
13.3 \\
9.2\end{array}$ & $\begin{array}{r}13.0 \\
7.5 \\
10.7 \\
8.7\end{array}$ \\
\hline
\end{tabular}

Table 4. Variance analysis on metallic chromium observed.

\begin{tabular}{|c|c|c|c|c|c|}
\hline Factor & d. f. & S. S. & m. S. & $\mathrm{F}_{0}$ & $\rho(\%)$ \\
\hline $\begin{array}{ll}\text { Heating method (A) } & \text { (A) } \\
\text { Heating time } & \text { (B) } \\
\text { Conc. of } \mathrm{H}_{2} \mathrm{SO}_{4} & \text { (C) } \\
\text { Size of sample } & \text { (E) } \\
\text { Reduction rate } & \text { (R) }\end{array}$ & $\begin{array}{l}1 \\
1 \\
1 \\
1 \\
1\end{array}$ & $\begin{array}{r}192.08 \\
49.01 \\
47.04 \\
5.12 \\
1200.50\end{array}$ & $\begin{array}{r}192.08 \\
49.01 \\
47.04 \\
5.12 \\
1200.50\end{array}$ & $\begin{array}{c}303^{* *} \\
77^{* *} \\
74 * * \\
8.09 * \\
1897^{* *}\end{array}$ & $\begin{array}{r}12.2 \\
3.1 \\
3.0 \\
0.3 \\
76.5\end{array}$ \\
\hline $\begin{array}{ll}\text { Interaction } & \mathrm{A} \times \mathrm{B} \\
& \mathrm{A} \times \mathrm{C} \\
& \mathrm{B} \times \mathrm{C} \\
& \mathrm{R} \times \mathrm{B} \\
& \mathrm{R} \times \mathrm{C}\end{array}$ & $\begin{array}{l}1 \\
1 \\
1 \\
1 \\
1\end{array}$ & $\begin{array}{r}8.00 \\
1.62 \\
5.78 \\
6.48 \\
17.41\end{array}$ & $\begin{array}{r}8.00 \\
1.62 \\
5.78 \\
6.48 \\
17.41\end{array}$ & $\begin{array}{l}12.6^{* *} \\
2.56 \\
9.13^{* *} \\
10.2^{* *} \\
28^{* *}\end{array}$ & $\begin{array}{l}0.5 \\
0.1 \\
0.3 \\
0.4 \\
1.1\end{array}$ \\
\hline $\begin{array}{l}\mathrm{R} \times \mathrm{A} \times \mathrm{B} \\
\mathrm{R} \times \mathrm{A} \times \mathrm{C} \\
\mathrm{R} \times \mathrm{B} \times \mathrm{C} \\
\mathrm{R} \times \mathrm{B} \times \mathrm{E}\end{array}$ & $\begin{array}{l}1 \\
1 \\
1 \\
1\end{array}$ & $\begin{array}{r}7.60 \\
12.50 \\
1.44 \\
3.92\end{array}$ & $\begin{array}{r}7.60 \\
12.50 \\
1.44 \\
3.92\end{array}$ & $\begin{array}{c}12.0^{* *} \\
19.8^{* *} \\
2.27 \\
6.19^{*}\end{array}$ & $\begin{array}{l}0.4 \\
0.8 \\
0.1 \\
0.2\end{array}$ \\
\hline$e^{\prime}$ & 17 & 10.76 & 0.633 & & 1.0 \\
\hline Total & 31 & 1569.26 & & & 100.0 \\
\hline
\end{tabular}

$\mathrm{F}_{17}^{1}(0.01)=8.40, \quad \mathrm{~F}_{17}^{1}(0.05)=4.45$

( $e^{\prime}$ includes factors whose $F_{0}$ are under 1.00) 
Table 5. Variance analysis on metallic iron observed.

\begin{tabular}{r|c|c|c|c|c}
\hline Factor & d. f. & S. S. & m. S. & $\mathrm{F}_{0}$ & $\rho(\%)$ \\
\hline Heating method (A) & 1 & 79.38 & 79.38 & $359^{* *}$ & 10.5 \\
Heating time (B) & 1 & 12.00 & 12.00 & $54^{* *}$ & 1.5 \\
Conc. of $\mathrm{H}_{2} \mathrm{SO}_{4}$ (C) & 1 & 16.53 & 16.53 & $75^{* *}$ & 2.2 \\
Size of sample (E) & 1 & 3.38 & 3.38 & $15.3^{* *}$ & 0.4 \\
Reduction rate (R) & 1 & 619.52 & 619.52 & $2803^{* *}$ & 82.2 \\
\hline Interaction $\quad \mathrm{A} \times \mathrm{B}$ & 1 & 3.13 & 3.13 & $14.2^{* *}$ & 0.4 \\
$\mathrm{~A} \times \mathrm{C}$ & 1 & 0.45 & 0.45 & 2.04 & 0.03 \\
$\mathrm{~B} \times \mathrm{C}$ & 1 & 2.54 & 2.54 & $11.5^{* *}$ & 0.3 \\
$\mathrm{R} \times \mathrm{B}$ & 1 & 2.88 & 2.88 & $13.0^{* *}$ & 0.4 \\
$\mathrm{R} \times \mathrm{C}$ & 1 & 3.00 & 3.00 & $13.6^{* *}$ & 0.4 \\
\hline $\mathrm{R} \times \mathrm{A} \times \mathrm{B}$ & 1 & 2.00 & 2.00 & $9.05^{* *}$ & 0.2 \\
$\mathrm{R} \times \mathrm{A} \times \mathrm{C}$ & 1 & 3.52 & 3.52 & $15.9^{* *}$ & 0.4 \\
$\mathrm{R} \times \mathrm{B} \times \mathrm{C}$ & 1 & 0.91 & 0.91 & 4.12 & 0.1 \\
$\mathrm{R} \times \mathrm{B} \times \mathrm{E}$ & 1 & 0.50 & 0.50 & 2.26 & 0.04 \\
\hline$e^{\prime}$ & 17 & 3.76 & 0.221 & & 0.8 \\
\hline
\end{tabular}

$\mathrm{F}_{17}^{1}(0.01)=8.40, \quad \mathrm{~F}_{17}^{1}(0.05)=4.45$

( $e^{\prime}$ includes factors whose $\mathrm{F}_{0}$ are under 1.00 )

Table 6. Cr and Fe segregation in each size range of pellet.

\begin{tabular}{c|c|c|c}
\hline Sample & $\begin{array}{c}\text { Range of size } \\
\text { (mesh) }\end{array}$ & $\begin{array}{c}\mathrm{Gr} \\
(\%)\end{array}$ & $\begin{array}{c}\mathrm{Fe} \\
(\%)\end{array}$ \\
\hline & $60 \sim 100$ & 11.5 & 11.2 \\
$\mathrm{~A}$ & $100 \sim 200$ & 12.7 & 11.4 \\
& $200 \sim 300$ & 14.6 & 11.6 \\
& -300 & 17.7 & 13.3 \\
\hline & $60 \sim 100$ & 9.0 & 10.0 \\
$\mathrm{~B}$ & $100 \sim 200$ & 11.6 & 10.2 \\
& $200 \sim 300$ & 13.7 & 9.5 \\
& -300 & 20.8 & 12.6 \\
\hline
\end{tabular}

対する効果と, 金属鉄に対する効果はほぼ同じ傾向を示 している、このうち寄与率ではペレットの還元率が，約 80\%を占めているが，これは当然である. 残りの要因 については, 試料重量 $(D)$ は有意でなく, 加熱方法 ( $A$ ) が最も大きい寄与率を示し, 加熱時間 $(B)$, 硫酸 濃度 $(C)$ がこれにつぎ試料䊀度 $(E)$ 沈危険率 $1 \%$ で 有意である.

まゔ試料粒度について考察する. Table 2 の 2 水準間 の差はやや有意であるので，60〜300メッシュにわたり 4 水準の粒度の試料を作成し，それぞれの範囲内での金 属クロムおよび金属鉄を分析した，その結果をTable 4 に示す.

この表から明らかなように，二種類の試料 A， B を 通じて，金属ク口ムおよび金属鉄の分析值に，粒度によ る差がみられ, 特に $300 \times ッ シ ュ$ 全通の試料は, 他の水 準のものに比し，高値を示している.これらのことから

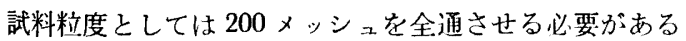

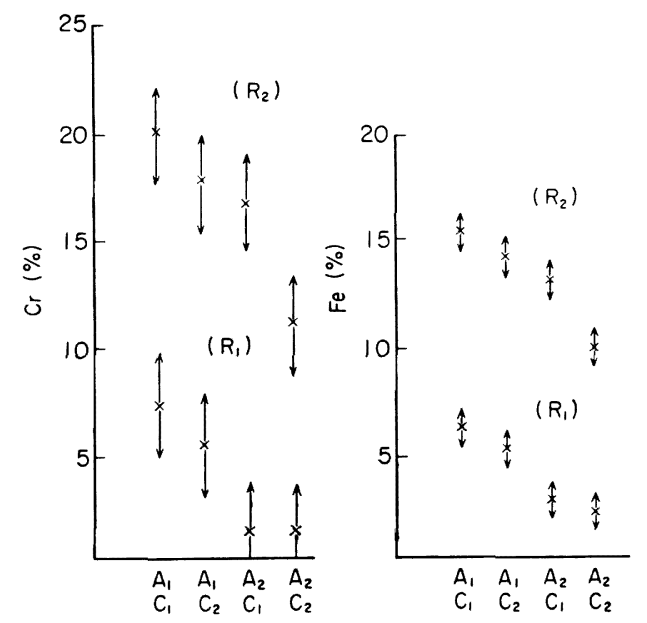

Fig. 3. Analysed value of $\mathrm{Cr}$ and $\mathrm{Fe}$ of sample $R_{1}$ and $R_{2}$ under various heating methods (A) and acid concentration (C).

と判断される.

ついで要因 $\mathrm{A}, \mathrm{B}$ および $\mathrm{C}$ について検討する. 分 散分析表から，交互作用にもかなりの影響がみられるの で，いま $\mathrm{A} \times \mathrm{C}$ および $\mathrm{A} \times \mathrm{B}$ について考察する. Fig. 3 は 99\%の信頼限界を入れたときの $\mathrm{A} \times \mathrm{C}$ の各水準の 特性值を示したものである.

還流器をつけてサンドバス上で加熱すると, 水浴上の オープン状加熱よりはるかに高い金属クロムおよび金属 鉄の值を得たかつその影響は酸濃度よりも大きく，水 浴上では硫酸 $(1+1)$ でも，十分な抽出は得られなかつ た。 
交互作用 $\mathrm{A} \times \mathrm{B}$ についても同じく $99 \%$ の信頼限界 を入れて Fig. 4 に図示した。

時閒の水準は，加熱方法によつて異なり水準 A 1 に刘 し，A 2 では 2 倍の侍間をかけた。にもかかわらず A 1 の方が A 2 より高い金属クロムおよび金属鉄の值を示し た．以上の検討から，水浴上のオープン状加熱では金属 クロムおよび金属鉄の抽出は，十分ではないと判断され る.

その理由として，水浴上の加熱はサンドバス上よりも 液温が低いためと考えられた。実際に各方法による硫酸 溶液の温度の経時变化を調べるため, 硫酸濃度 $(1+1)$, $(1+3) ，(1+10)$ の 3 水準について Fig. 5 に示される 加熱方法のもとで，液温の時間による変化を調べた。
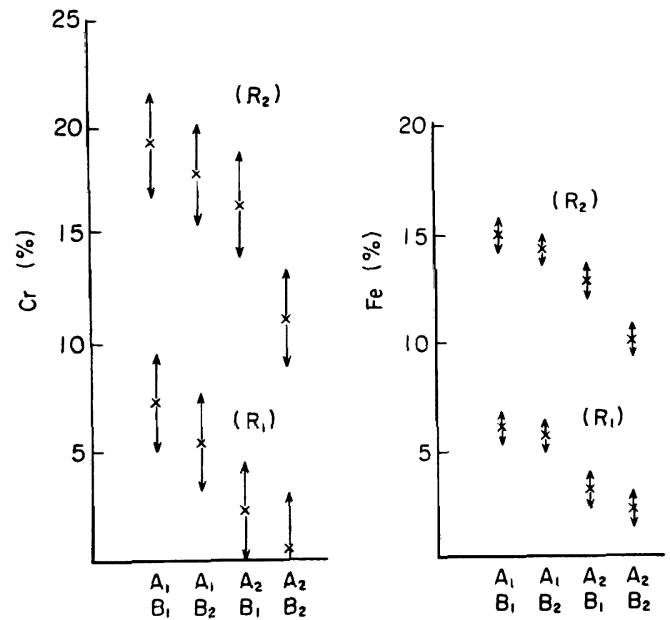

Fig. 4. Analysed value of $\mathrm{Cr}$ and $\mathrm{Fe}$ of sample $R_{1}$ and $R_{2}$ under various heating methods (A) and heating time (B).

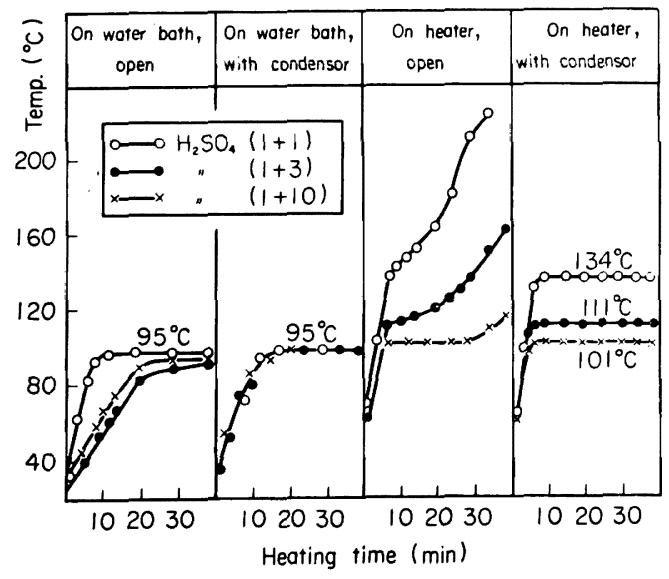

Fig. 5. Solution temperature of sulfuric acid with various concentration.
この結果から水浴上では硫酸濃度のいかんにかかわら ず，最高は $95^{\circ} \mathrm{C}$ であつた．従来，温度指示として与え られていた $80^{\circ} \mathrm{C}$ という值は実際上一定に維持しにくい 温度であることも明らかになつた。一方，ヒーター上で オープン加熱すると液は次第に濃縮され，このため液温 は上昇しついには白煙が発生するに至る。このとき還流 冷却器をとりつけて加熱すると液の濃度は一定となり, その沸点を維持する，かくして，例えば硫酸 $(1+1)$ で は $134^{\circ} \mathrm{C},(1+3)$ では $111^{\circ} \mathrm{C},(1+10)$ では $101^{\circ} \mathrm{C}$ が得られた。

\section{2 鉱石中の酸化クロムおよび酸化鉄の溶出}

硫酸濃度として，いかなる濃度が適当であるかについ てはペレット中の金属クロムおよび金属鉄の抽出率とと

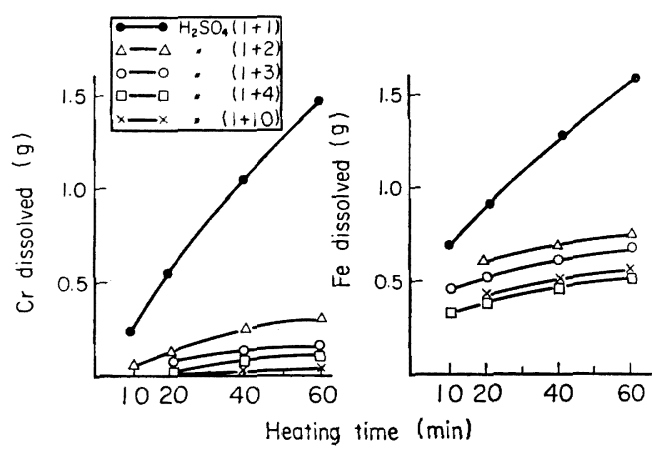

Fig. 6. Dissolved quautity of $\mathrm{Cr}$ and $\mathrm{Fe}$ per $100 \mathrm{~g}$ of chromite ore under various $\mathrm{H}_{2} \mathrm{SO}_{4}$ concentration.

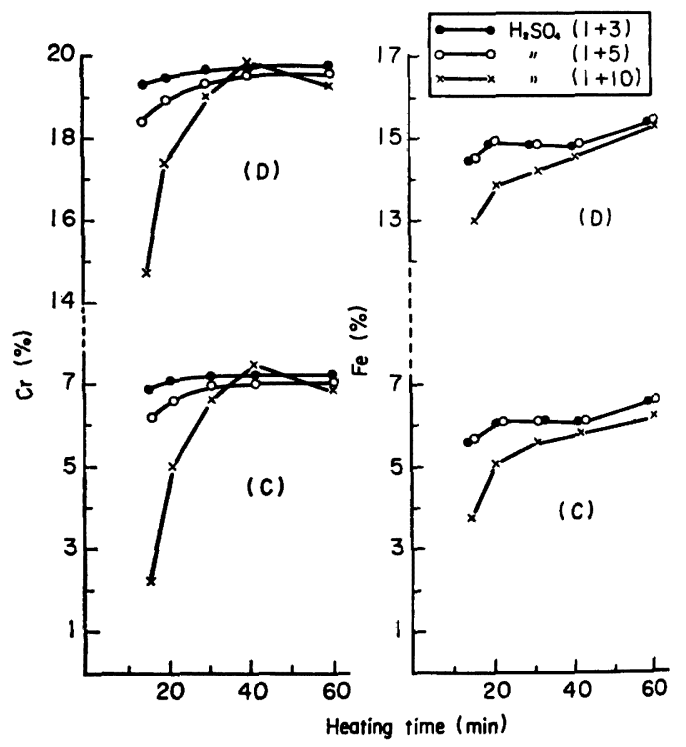

Fig. 7. Analysed value of $\mathrm{Gr}$ and $\mathrm{Fe}$ of pellet under various sulfuric acid_concentration. 
もに，末反応のクロム鉱石からの酸化クロムおよび酸化 鉄の溶出量についても考虑せ权ばならない。この目的か らクロム $33.8 \%$ ，鉄 $14.0 \%$ を含有するクロム鉱石を 用い, 硫酸濃度 $(1+1) \sim(1+10)$ の範囲にわたつて酸化 クロムおよび酸化鉄の溶出量を求めた. 実験方法は \$1 に準じ，溶出せるクロム抢よび鉄の量をクロム鉱石 100 g当りで表示し Fig. 6 に示した.

この図より，硫酸 $(1+1)$ は濃厚なためクロム鉱石の 溶解が大きく不適当であり, 実際的には硫酸 $(1+3)$ よ り薄い濃度が好ましいと判断された。 そこで, 硫酸 $(1+$ $3),(1+5),(1+10)$ の各濃度の液についてペレット試 料 $\mathrm{C}, \mathrm{D}$ の 2 種類について金属クロムおよび金属鉄の分 析を行なつた. その結果を Fig. 7 に示す.

この結果から硫酸 $(1+10)$ では抽出に長い時間を要 し, $(1+3)$ 又は $(1+5)$ では $30 \mathrm{~min}$ で一定の值が得ら れることがわかつた。したがつて硫酸 $(1+3)$ を用いて $30 \mathrm{~min}$ 間抽出する方法を採用することにした。

通常, 半還元ペレット中に残存するクロム鉱石の量は 30\% 程度と考えられるので，かりに Fig. 6 から硫酸 $(1+3)$ によるクロム鉱石の溶出量をクロムで $0.15 \mathrm{~g}$,

鉄で $0.6 \mathrm{~g}$ （鉱石 $100 \mathrm{~g}$ 当り）とすると試料 $0.5 \mathrm{~g}$ につ き鉱石からの流出量の寄与はク口ムで $0.2 \mathrm{mg}$, 鉄で 0.9 $\mathrm{mg}$ 程度で分析結果として, クロムで $0.04 \%$, 鉄で 0.18 \%程度である.したがつて硫酸 $(1+3)$ を用いる時は鉱 石からの酸化クロムや酸化鉄の溶出量は無視できるほど 小さい.

\section{3 分析所間の比較}

上記検討結果から金属クロムおよび金属鉄の分析法を 次のように改訂した。

試料は 200 ×ッシュ以下に粉砕調製し， $0.5 \mathrm{~g}$ をはか り取つて硫酸 $(1+3) 50 \mathrm{ml}$ を加え，ヒ一タ一上で加熱 する。この時, 還流冷却器をつけて温度および硫酸浱度 を一定に保つ. $30 \mathrm{~min}$ 間抽出の後, 沪過して, 沪液を 用いて \&1 と同じくJISG 1313 および JISM 8263 に よりクロムおよび鉄を測定する.

以上の改訂案と, 比較のため硫酸 $(1+1)$ を用いて改 訂法に従い，加熱時間を $20 \mathrm{~min}$ とした場合および §1 の従来法の三方法によつて比較を行なつた．分析所は,

$\mathrm{R}, \mathrm{X}, \mathrm{Y}, \mathrm{Z}$ の 4 力所とし, 日内くりかえし 2 回, 日 間くりかえし 2 回, 試料は高還元品と低還元品の 2 種を 用いて実験を行なつた．その結果を Fig. 8 および 9 に またこの結果から求めた分析精度を Table 7 に示す.

従来法は分析所間の差が大きく，またバラッキも大き い. 改良案の硫酸 $(1+3)$ と硫酸 $(1+1)$ は Fig. 8, 9 ではよく似た結果を示しているが， Table 7 にみられ

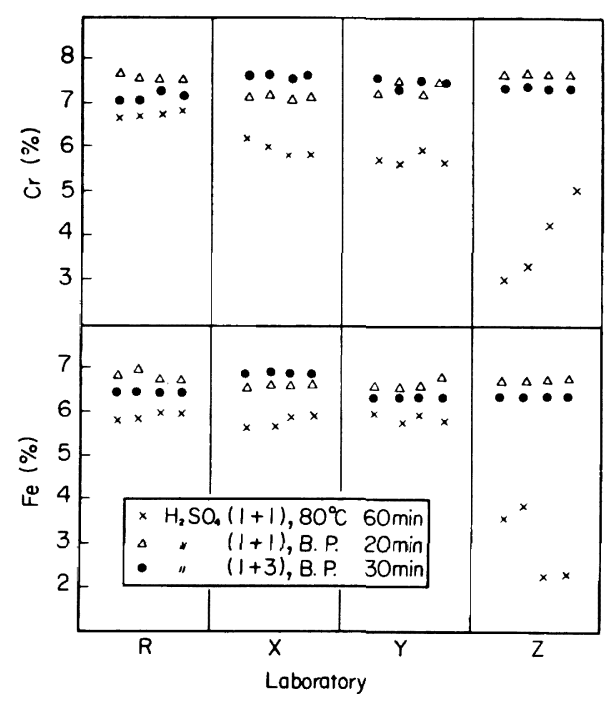

Fig. 8. Analysed value of $\mathrm{Cr}$ and $\mathrm{Fe}$ of lower reduced pellet by four laboratories.

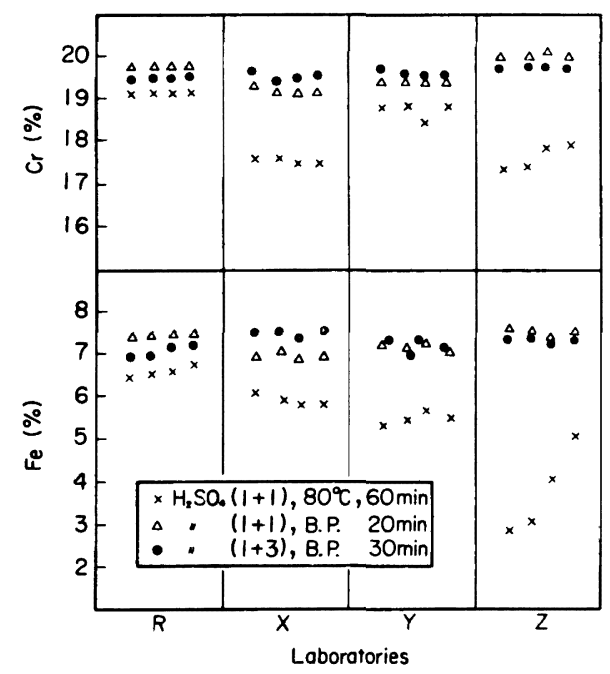

Fig. 9. Analysed value of $\mathrm{Cr}$ and $\mathrm{Fe}$ of higher reduced pellet by four laboratories.

るように $(1+3)$ の方が精度がすく㞦ている。かつまた クロム鉱石からの溶出も考えると, 抽出時間の差, $10 \mathrm{~min}$ はほとえど評俩に值せず，改訂案が最善と判断された。

4. 結

論

高炭素フェロクロム製造時の子供還元工程で製造され た半還元クロムペレット中の金属クロムおよび金属鉄の 定量法について研究を行ない次の結論を得た。

試料 $0.5 \mathrm{~g}$ を $200 \times ッ シ ュ$ 全通とし硫酸 $(1+3) 50 \mathrm{ml}$ で $30 \mathrm{~min}$ 間, 還流冷却器をつけてヒーター上で加熱す 
Table 7. Precision of analysis.

\begin{tabular}{|c|c|c|c|c|c|c|}
\hline \multirow{2}{*}{$\overline{\mathrm{E}} \mathrm{C}$} & \multicolumn{3}{|c|}{$\mathrm{Cr}$} & \multicolumn{3}{|c|}{$\mathrm{Fe}$} \\
\hline & $1+1$ & $1+1$ & $1+3$ & $1+1$ & $1+1$ & $1+3$ \\
\hline & 80 & B.P. & B.P. & 80 & B.P. & B.P. \\
\hline Term of $\sigma$ & 60 & 20 & 30 & 60 & 20 & 30 \\
\hline $\begin{array}{l}\text { Between labos } \\
\text { Between days } \\
\text { Sample } \times \text { labos } \\
\text { Within day } \\
\text { Total }\end{array}$ & $\begin{array}{l}0.85 \\
0.39 \\
0.55 \\
0.17 \\
1.10\end{array}$ & $\begin{array}{l}0.25 \\
0.03 \\
0.05 \\
0.07 \\
0.27\end{array}$ & $\begin{array}{l}0.09 \\
0.06 \\
0.08 \\
0.07 \\
0.15\end{array}$ & $\begin{array}{l}0.92 \\
0.41 \\
0.61 \\
0.11 \\
1.18\end{array}$ & $\begin{array}{l}-\overline{-} \\
0.07 \\
0.15 \\
0.09 \\
0.19\end{array}$ & $\begin{array}{l}0 . \overline{0} \\
0.17 \\
0.05 \\
0.20\end{array}$ \\
\hline
\end{tabular}

E : Element, $\mathrm{C}$ : Conc. of $\mathrm{H}_{2} \mathrm{SO}_{4}$, ${ }^{*}$ : Temp. $\left({ }^{\circ} \mathrm{C}\right)$, ${ }^{* *}$ : Time (min)

ると，液温は約 $111^{\circ} \mathrm{C}$ に保たれ，金属クロムおよび金 属鉄はほぼ完全に抽出される．末還元のクロム鉱石から の酸化クロムおよび酸化鉄の溶出は無視できるほど小さ い.この方法によるときの分析精度は，金属クロムでは 平均 $13.6 \%$ に対し $\sigma=0.15 \%$ ，金属鉄では平均 $7.4 \%$ に対し $\sigma=0.20 \%$ であつた。 また分析時間の差はみら れずよく一致した。

\section{交献}

1）特公昭 36-2153，合金用の焼結した塊状添加剂

2) R. R. LloYD, "Chromium" Vol II, (Ed. M.J. UDY), 1956, p. 51 Reinhold Pub. Corp., (New York)

3 ）菊池武昭，黑沢利夫，楖橋哲夫：日本金属学会誌 32, p. 866 (1968)

4 ) A. SCHE1: Norweigian Journal of Chemistry, Mining and Metallurgy, 27 (1967) No. 8, 9, p. $152 \sim 158$ 